\title{
Estimation of Costs and Durations of Construction of Urban Roads Using ANN and SVM
}

\author{
Igor Peško, Vladimir Mučenski, Miloš Šešlija, Nebojša Radović, Aleksandra Vujkov, \\ Dragana Bibić, and Milena Krklješ
}

University of Novi Sad, Faculty of Technical Sciences, Trg Dositeja Obradovica 6, Novi Sad, Serbia

Correspondence should be addressed to Igor Peško; igorbp@uns.ac.rs

Received 27 June 2017; Accepted 12 September 2017; Published 7 December 2017

Academic Editor: Meri Cvetkovska

Copyright (C) 2017 Igor Peško et al. This is an open access article distributed under the Creative Commons Attribution License, which permits unrestricted use, distribution, and reproduction in any medium, provided the original work is properly cited.

\begin{abstract}
Offer preparation has always been a specific part of a building process which has significant impact on company business. Due to the fact that income greatly depends on offer's precision and the balance between planned costs, both direct and overheads, and wished profit, it is necessary to prepare a precise offer within required time and available resources which are always insufficient. The paper presents a research of precision that can be achieved while using artificial intelligence for estimation of cost and duration in construction projects. Both artificial neural networks (ANNs) and support vector machines (SVM) are analysed and compared. The best SVM has shown higher precision, when estimating costs, with mean absolute percentage error (MAPE) of 7.06\% compared to the most precise ANNs which has achieved precision of $25.38 \%$. Estimation of works duration has proved to be more difficult. The best MAPEs were $22.77 \%$ and $26.26 \%$ for SVM and ANN, respectively.
\end{abstract}

\section{Introduction}

Civil engineering presents a specific branch of industry from all aspects. The main reason for this lies in specific features of construction objects as well as the conditions for their realisation. Another specific aspect of realisation of construction projects is that the realisation process involves a large number of participants with different roles. The key role in the realisation of construction processes is certainly played by an investor, who is at the same time the initiator of realisation of a construction project, whose main goal is to choose a reliable contractor who can guarantee the fulfilment of set requirements (costs, time, and quality).

When choosing a constructor, a dominant parameter is the offered cost of realisation, which implies that it is necessary to carry out an adequate estimation of construction costs. The question that arises is which costs, that is, which price, should be the subject of estimation. Gunner and Skitmore [1] and Morrison [2] based their research which relates to the estimation of realisation costs, on the lowest price offered. However, according to Skitmore and Lo [3], very often the lowest price does not reflect actual realisation costs, since contractors offer services at unrealistically low prices. Azman et al. [4] quote the recommendation of Lowe and Skitmore to accept the second lowest offer, as the very lowest one does not guarantee the actual value. They also mention the suggestion made by McCaffer to use the mean value of submitted offers for estimation, rather than the lowest one, explaining that it is the closest to the actual price.

Some authors, however, Aibinu and Pasco [5], use the values given in the accepted offer for the needs of estimating the accuracy of predicted values, since it is the value accepted by the investor. Abou Rizk et al. [6] and Shane et al. [7] recommend the use of actually paid realisation value. Nevertheless, Skitmore [8] explains that there are certain problems when using actually paid values for realisation, with the main one residing in the fact that the data is not easily available, and even if they are, they are often not properly recorded, that is, are not real. Moreover, there is a problem of time between the forming of cost estimation and realisation of real costs, in which significant changes in the project may occur during the realisation process, which can influence the amount of contracted works for which the offer was formed.

According to everything mentioned above, the estimation of costs within this research was carried out based on the realisation value offered by the contractor. 
Further on, there are two levels of estimation of potential works from the perspective of a contractor, which precede the realisation of contracting, and those are conceptual (rough) and preliminary (detailed) estimation [9]. Conceptual estimation of costs usually results in the total number without the detailed analysis of the structure of costs. This implies that conceptual estimation should use simpler and specialised estimation models. Its contribution is the assessment of justifiability of following work on the project in question, or more precisely further work on preliminary estimation which is carried out prior to signing of a contract. The basis for both estimations is the data about the object provided by the investor, that is, tender documentation. The question arises on what accuracy of estimation is acceptable. The required, acceptable accuracy of estimation of construction costs from the perspective of a contractor in the initial phase of tender procedure (conceptual estimation) according to Ashworth [10] amounts to $\pm 15 \%$. This is the accuracy which was adopted in this research as the basic goal of precision of formed models for the estimation of construction costs.

It was noted that the dominant parameter for choosing the most favourable contractor is the offered price. However, the proposed time for realisation of works in question should not be neglected either. The main problem of estimation of duration of works in the conceptual phase is the fact that the potential contractor does not possess realisation plans, which implies the application of estimation methods which provide satisfactory accuracy based on data available at a time. It is a common case for an investor to limit the maximum duration of construction in the tender conditions.

Having in mind that it is necessary to carry out simultaneous estimation of costs and duration of the construction process, the fact that the research confirmed that the costs of significant position of works are at the same time of temporal significance is highly important $[11,12]$. The previously mentioned statement is significant for the processes of planning and control of time during the realisation of a construction project and confirms the justifiability of simultaneous estimation of costs and duration of contracted works.

It was mentioned that conceptual estimation requires application of simpler and specialised models with an acceptable accuracy of estimation. One of the possible approaches is the application of artificial intelligence (artificial neural networks (ANNs), support vector machine (SVM), etc.). The basic precondition for the application of this approach is the forming of an adequate base of historical data on similar construction projects previously realised.

\section{ANN and SVM Applications in Construction Industry}

The first scientific article related to the application of ANNs in construction industry was published by Adeli in the Microcomputers in Civil Engineering magazine [13]. The application becomes more frequent along with software development. The sphere of application of ANNs and the SVM in construction industry is very wide and present in basically all phases of realisation of a project, from its initialising, through designing and construction, to maintenance, renovation, demolishing, and recycling of objects. Some of the examples of their application are estimation of necessary resources for realisation of projects [14], subcontractor rating [15], estimation of load lifting time by using tower cranes [16], noting the quality of a construction object [17], application in carrying out of economic analysis [18], application in the case of compensation claims $[19,20]$, construction contractor default prediction [21], prequalification of constructors [22], cash flow prediction [23], project control forecasting [24], estimation of recycling capacity [25], predicting project performance [26], and many others.

Cost estimation by using ANNs and SVM is often represented in the literature, for example, estimation of construction costs of residential and/or residential-commercial facilities [27, 28], cost estimation of reconstruction of bridges [29], and cost estimation of building water supply and sewerage networks [30]. In his master thesis, Siqueira [31] addresses the application of ANN for the conceptual estimation of construction costs of steel constructions. An et al. [32] showed the application of SVM in the assessment process of construction costs of residential-commercial facilities. In addition to the mentioned authors, the application of ANNs and SVM for the estimation of construction costs was dealt with by Adeli and $\mathrm{Wu}$ [33], Wilmot and Mei [34], Vahdani et al. [35], and many others.

Kong et al. [36] carried out the prediction of cost per $\mathrm{m}^{2}$ for residential-commercial facilities by using SVM. Kong et al. [37] carried out the comparison of results of price prediction for the same data base by using a SVM model and RSSVM model (RS, rough set).

Kim et al. [38] carried out a comparative analysis of results obtained through ANN, SVM, and regression analysis for cost estimation of school facilities. This presents a rather common case in available and analysed literature. Not only the comparative analysis of ANN an SVM models with other models for solving of the same types of problems, but also its combining with other forms of artificial intelligence, such as fuzzy logic (FL) and genetic algorithms (GA), is carried out, where the so-called hybrid models are created. Kim et al. [39] compared models for cost estimation of the construction of residential facilities, based on multiple regression analysis (MRA), artificial neural networks (ANNs), and case-based reasoning (CBR). Sonmez [40] also drew a parallel between an ANN model for conceptual estimation of costs with a regression model. Kim et al. [41] and Feng et al. [42] used genetic algorithms (GA) in their research when defining an ANN model for cost estimation of construction of buildings, as a tool for optimisation of the ANN model itself. In addition to combining with GA, there is also the possibility of combining an ANN with fuzzy logic (FL), where hybrid models are created as well. The application of ANN-FL hybrid models for the estimation of construction costs was used in the research of Cheng and Huang [43] and Cheng et al. [44]. Cheng and $\mathrm{Wu}$ [45] outlined the comparative analysis of models for conceptual estimation of construction costs, formed by using of ANN, SVM, and EFNIM (evolutionary fuzzy neural inference model). Deng and Yeh [46] showed the use of LSSVM (LS, least squares) model in the cost prediction process. Cheng et al. [47] connected two approaches of artificial 
intelligence (fast genetic algorithm (fmGa) and SVM) for the purpose of estimation of realisation of construction projects (e.g., prediction of \% completeness of $i$ th, period in the realisation of the construction project). This model is called ESIM (evolutionary support vector machine inference model).

Since the topic of the research is the estimation of costs and duration of construction of urban roads, the following text will contain research carried out on similar types of constructions. Wang et al. [48] showed in their work the estimation of costs of highway construction by using ANNs. Including the set of 16 realised projects, they carried out the training (first 14 projects) and validation (remaining 2 projects) of the ANN model. Al-Tabtabai et al. [49] surveyed five expert project managers, defining the factors which influence the changes in the total costs of highway construction, such as location, maintaining of the existing infrastructure, type of soil, consultant's capability of estimation, construction of access roads, the distance of material and equipment transportation, financial factors, type of urban road, and the need for obtaining of a job.

Hegazy and Ayed [50] provided an overview of forming of a model by using ANNs for the parameter estimation of costs of highway construction. They use the data obtained from 18 offers by anonymous bidders for the realisation of works on highway construction in Canada, 14 offers for training, and 4 offers for testing. Sodikov [51] gave an outline of the estimation of costs of highway construction by applying ANNs. The analysis and formation of model were performed based on two sets of data from different locations. The first set of data was formed based on the projects realised in Poland (the total of 135 projects, with 38 realised projects on highway construction used for the analysis) and the second based on projects realised in Thailand (the total of 123 projects, with 42 realised projects on asphalt layer "coating"). It is important to note that Hegazy and Ayed [50] as well as Sodikov [51], used the duration of works realisation as the input parameter. This duration is also unknown in the process of defining of the conceptual estimation, as is the cost of realisation of works. El-Sawahli [52] performed the estimation of costs of road construction by using a SVM model formed according to the base of 70 realised projects in total.

Estimation of duration of the construction of buildings by using ANNs and SVM is not present in the literature, as it is the case with estimation of costs. Attal [53] formed independent and separate ANN models for estimation of costs and duration of highway construction. Bhokha and Ogunlana [54] defined an ANN model for prediction of duration of multistorey buildings construction in a preproject phase. Hola and Schabowicz [55] carried out the estimation of duration and costs of realisation of earthworks by using an ANN model. Wang et al. [56] performed the predicting of construction cost and schedule success by applying ANN and SVM.

\section{Material and Methods}

Within the research carried out, gathering of data and data analysis were performed, followed by the preparation of data for the needs of model formation, as well as the final forming of models and their comparative analysis.
Gathering of data and forming of the data base on realised construction projects of reconstruction and/or construction of urban roads were carried out on the territory of the city of Novi Sad, the Republic of Serbia. All the projects were funded by the same investor in the period between January 2005 and December 2012. All the projects solely relate to the realisation of construction works based on completed projects and technical documentation. Having in mind everything mentioned above, uniform tender documentation, that is, the bill of works which makes its integral part, served as the main source of information.

The sample comprises 198 contracted and realised construction projects. However, not all of the projects were included in the analysis carried out later on, owing it to the fact that certain projects, 32 of them in total, include realisation of works on relocation of installations (sewerage, water, gas, etc.), green spaces landscaping, street lighting, and construction of supporting facilities on the roads (smaller bridges, culverts, etc.), which are excluded from further analysis.

The total number of realised projects included in the further analysis amounts to 166 projects of basic construction works and/or reconstruction of urban roads. As it has been already noted, all projects were realised for the same investor. Consequently, the tender documentation is uniform, which is also the case with the distribution of works within the bill of works, dividing them into preparation works, earthworks, works on construction of pavement and landscaping, drainage works, works on construction of traffic signals, and other works.

The analysis of the share of costs of the mentioned work groups in the total offered price of realisation was carried out. This confirmed that the works on roadway structure and landscaping have the biggest impact on the total price, ranging within the interval from $22.24 \%$ to $100 \%$ (only two cases where only these two types of works were planned). Earlier research included similar analysis, but only for projects realised by the same contractor $[57,58]$.

Table 1 shows mean values of the percentage of works groups in the total offered value for realisation of works. The interval between $65 \%$ and $95 \%$ of the amount of works on the roadway construction and landscaping within the total offered price includes 106 projects, that is, $63.86 \%$ of the total number of analysed projects. The total number of potential work positions which may occur during the realisation of all basic works is 91 (according to the general section of tender documentation, which is the same for all analysed projects), whereas the total number of potential positions from the bill of works related to roadway construction and landscaping works amounts to 18 . Percentage share of activities related to roadway construction and landscaping in relation to the total number of potential positions amounts to $19.78 \%$, which is approximately the same as the percentage of cost-significant activities according to "Pareto" distribution, which amounts to $20 \%$.

Considering the fact that for $63.86 \%$ of analysed projects the share of the total price ranges within the interval between $\pm 15 \%$ and $80 \%$ of the total offered value, it can be stated that the works on roadway construction and landscaping are 
TABLE 1: Mean values of the percentage of works groups in the total offered value.

\begin{tabular}{lcc}
\hline Number & Group of works & Mean value of the percentage of works groups in the total offered price [\%] \\
\hline$(1)$ & Roadway construction and landscaping works & 68 \\
$(2)$ & Earthworks & 14 \\
$(3)$ & Preparation works & 12 \\
$(4)$ & Other works & 3 \\
$(5)$ & Drainage works & 2 \\
$(6)$ & Works on traffic signals installation & 1 \\
\hline
\end{tabular}

TABLE 2: Number of projects according to the offered number of days for realisation.

\begin{tabular}{lccc}
\hline Number & $\begin{array}{c}\text { Offered number } \\
\text { of days }\end{array}$ & $\begin{array}{c}\text { Number of } \\
\text { projects }\end{array}$ & $\begin{array}{c}\text { Percentage share } \\
\text { in the data base } \\
{[\%]}\end{array}$ \\
\hline$(1)$ & Up to 20 & 50 & 30.12 \\
$(2)$ & 21 to 30 & 31 & 18.67 \\
$(3)$ & 31 to 40 & 24 & 14.46 \\
$(4)$ & 41 to 50 & 26 & 15.66 \\
$(5)$ & 51 to 60 & 5 & 3.43 \\
$(6)$ & 61 to 70 & 7 & 3.01 \\
$(7)$ & 71 to 80 & 4 & 2.22 \\
$(8)$ & 81 to 90 & 5 & 3.01 \\
$(9)$ & Above 90 & & 51 \\
\hline
\end{tabular}

cost-significant according to "Pareto" distribution, that is, distribution of $20 / 80$. This is an additional reason why these works play the major role when defining an estimation model. Realisation of works on roadway construction and landscaping relates to usage of basic materials, such as crushed stone (different fractions), curbs, asphalt base layer, asphalt surface layer, and concrete prefabricated elements for paving.

Duration of realisation is offered in the form of the total number of days and there is no way in which it can be claimed with certainty how much time is needed for the realisation of each group of works individually. For this reason, classification of projects was carried out based solely on the total amount of time offered for the realisation of all planned works. Table 2 shows the number of projects according to the offered number of days for realisation. According to some research, cost-significant work positions are durationsignificant as well $[11,12]$. Hence, it is of equal importance to put particular emphasis on works related to roadway construction and landscaping, both from the perspective of cost estimation and from the duration of the realisation process.

Estimation of costs, as well as all the other estimations such as duration of realisation, involves the engagement of resources. According to the literature, estimation of costs ranges between $0.25 \%$ and $1 \%$ of the total investment value [59]. For this reason, Remer and Buchanan [60] developed a model for estimating of costs for the work (cost) estimation process. The reason for such research lies in the fact that lowcost estimates can lead to unplanned costs in the realisation process and/or in lower functional features of an object than those required by the investor.
The primary purpose of forming of an estimation model is to perform the most accurate estimation possible in the shortest interval of time possible, with the minimum engagement of resources, all of it based on the data available at the time of estimation. Since the contracts in question are the so-called "build" contracts, an integral part of tender documentation is the bill of works, or more precisely the amount of works planned in the project-technical documentation. Estimations of costs based on amounts and unit prices are the most accurate ones but require a great amount of time and need to be applied in preliminary (detailed) estimation, which precedes directly the signing of a contract. However, conceptual (rough) estimation which results in the total costs of realisation requires simpler and faster methods of estimation. With the aim of defining a method featuring such performances, a formerly presented analysis of significance and impact of groups of works on the total price, both on total costs and on realisation time, was carried out.

The works on roadway construction and landscaping, as the most important group of works, were considered in more detail in comparison with other groups of works; that is, they were assigned greater significance. Having in mind the characteristics of works performed within this group, a large amount of material necessary for their realisation being one of them, the input parameters for creating of this model are the amounts of material necessary for their realisation (Table 4).

Despite the fact that the mean percentage share of roadway construction and landscaping works amounts to $68 \%$, the share of the remaining groups of works in the total 
TABLE 3: Number of projects depending on the offered revalorised price for realisation of works.

\begin{tabular}{|c|c|c|c|}
\hline Number & Offered price for realisation [RSD] ${ }^{*}$ & Number of projects & Percentage share in data base [\%] \\
\hline (1) & Up to $5,000,000$ & 32 & 19.2 \\
\hline$(2)$ & From $5,000,000$ to $10,000,000$ & 28 & 16.87 \\
\hline (3) & From $10,000,000$ to $20,000,000$ & 24 & 14.46 \\
\hline$(4)$ & From $20,000,000$ to $30,000,000$ & 19 & 11.45 \\
\hline$(5)$ & From $30,000.000$ to $40,000,000$ & 13 & 7.83 \\
\hline$(6)$ & From $40,000,000$ to $60,000,000$ & 8 & 4.82 \\
\hline$(7)$ & From $60,000,000$ to $100,000,000$ & 21 & 12.65 \\
\hline$(8)$ & From $100,000,000$ to $200,000,000$ & 13 & 7.83 \\
\hline$(9)$ & Over $200,000,000$ & 8 & 4.82 \\
\hline
\end{tabular}

${ }^{*}$ RSD: Republic Serbian Dinar (1 EUR = 122 RSD).

TABLE 4: Inputs into models.

\begin{tabular}{|c|c|c|c|c|c|c|}
\hline Number & Description of input data & Data type & $\begin{array}{c}\text { Unit of } \\
\text { measurement }\end{array}$ & Min & Max & $\begin{array}{l}\text { Mean } \\
\text { value }\end{array}$ \\
\hline Input 1 & Amount of crushed stone & Numerical & $\mathrm{m}^{3}$ & 0,00 & $16,070.00$ & $1,694.62$ \\
\hline Input 2 & Amount of curbs & Numerical & $\mathrm{m}^{1}$ & 0,00 & $14,300.00$ & $1,975.07$ \\
\hline Input 3 & Amount of asphalt base layer & Numerical & $\mathrm{t}$ & 0,00 & $31,569.00$ & $1,119.61$ \\
\hline Input 4 & Amount of asphalt surface layer & Numerical & $\mathrm{t}$ & 0,00 & $11,046.00$ & 505.85 \\
\hline \multirow[t]{2}{*}{ Input 5} & Amount concrete prefabricated elements & Numerical & $\mathrm{m}^{2}$ & 0,00 & $20,000.00$ & $2,824.85$ \\
\hline & Percentage share of wok positions & & & & & \\
\hline Input 6 & Preparation works & Numerical & $\%$ & 0,00 & 100.00 & 43.18 \\
\hline Input 7 & Earthworks & Numerical & $\%$ & 0,00 & 100.00 & 48.92 \\
\hline Input 8 & Drainage works & Numerical & $\%$ & 0,00 & 93.33 & 16.63 \\
\hline Input 9 & Traffic signalisation works & Numerical & $\%$ & 0,00 & 100.00 & 28.66 \\
\hline Input 10 & Other works & Numerical & $\%$ & 0,00 & 100.00 & 8.59 \\
\hline Input 11 & Works realisation zone & Discrete & - & 1 & 2 & - \\
\hline Input 12 & $\begin{array}{l}\text { Project category (values of up to and over } \\
40,000,000)\end{array}$ & Discrete & - & 1 & 2 & - \\
\hline
\end{tabular}

offered value should not be neglected. The biggest share in the total offered value for realisation of the remaining groups of works belongs to earthworks and preparation works, whereas traffic signals, other works, and drainage contribute with a considerably lower percentage (Table 2).

Inclusion of the mentioned works in further analysis was carried out based on the number of planned positions of works for each individual bid project in relation to a possible number of positions of works (according to a universal list issued by the investor) in groups of works, directly through percentage share (Table 4).

Moreover, it was noticed that it is possible to classify realised works based on the location they were supposed to be realised on. For that purpose, realisation of works was divided into two zones: zone 1, realisation of works in the city centre, and zone 2, realisation of works in the suburbs (Table 4).

Since the research carried out relates to the financial aspect of realisation of construction projects, it is necessary to perform revalorisation, in order for the data to be comparable and applicable to forming of an estimation model by using artificial intelligence. By using the revalorisation process, defining of difference is achieved, that is, the increase or decrease of offered values for the realisation of works in relation to the moment in which the estimation of realisation costs for future projects will be made, by applying the model. In other words, by applying the revalorisation process, the changes in the prices defined on the base date in relation to the current date will be defined. Base date is the date on which the contracted price was formed (i.e., giving an offer), whereas the current date presents the date on which the revalorisation is carried out.

Revalorisation is made based on the index of general retail prices growth in the Republic of Serbia, where the \% increase in the period between February 2005 and July 2012 amounted to $95.47 \%$, which is close to the mean value of increase of $89.91 \%$, obtained on the basis of the values of unit prices from two final offers. After the completed revalorisation, the contracted (offered) values of realised works are directly comparable; that is, they can be classified based on the total offered revalorised value for the realisation of works (Table 3).

Classification of projects according to the total value for the realisation of works can be of great importance when training/testing of formed models for estimation. For that reason, an additional input parameter was introduced, which 
TABLE 5: Outputs from the models.

\begin{tabular}{lcccccc}
\hline Number & Input data description & Data type & Unit of measure & Min & Max & Mean value \\
\hline Output 1 & Total offered cost of realisation & Numerical & RSD & $883,353.01$ & $395,427,276.11$ & $45,705,301.56$ \\
Output 2 & Total offered duration of realisation & Numerical & day & 5 & 120 & $\approx 38$ \\
\hline
\end{tabular}

divides projects into two subsets (values of up to and over 40,000,000 RSD) (Table 4). The borderline was defined based on the number of projects whose value does not exceed $40,000,000 \mathrm{RSD}$, which is $70 \%$ of the total number of analysed projects, whereas the mean value of offered price for all the projects is also approximately similar to this value (Table 5).

According to the previously defined subject of study, two outputs from the model were planned, the total offered price for realisation and total amount of time offered for the realisation of a project.

The next step in preparing of the data base is the normalisation process. Normalisation of data presents the process of reducing of certain data to the same order of magnitude. What is achieved in this way is for the data to be analysed with the same significance when forming a prediction model, that is, to avoid neglecting of data with a smaller order of magnitude range at the very beginning. This is the main reason why the normalisation is necessary; that is, why it is essential to transform the values into the same range by moving the range borderlines. The normalisation process was carried out for the entire set of 166 analysed projects.

Before the normalisation process is applied, considering the fact that a model based on artificial intelligence will be formed, it is necessary to divide the final set of 166 projects into a set that will be used for the training of a model, as well as the one used for the testing of formed models. Defining of which data subset will be used for the training of a model and which one for its testing, is not entirely based on the random sample method. The comparative analysis was carried out of the number of projects by categories based on the offered revalorised total price as well as the offered time for realisation of all works.

When choosing the projects that belong to the training subset, particular attention was paid to the fact that the minimum and maximum values of all parameters belong to the range of this set. In addition, all groups of projects should be equally present in both sets, according to the offered value and time for realisation. Finally, the testing subset comprised 17 pseudorandomly chosen projects (with mentioned restrictions), whereas the remaining 149 projects constitute the training subset.

The most commonly used forms of data normalisation, being the simplest ones at the same time, are the minmax normalisation and Zero-Mean normalisation [61], which were applied in the conducted research.

The first step in forming of models for estimation by using ANNs relates to defining of the number of hidden layers. According to Huang and Lipmann [62] there is no need to use ANNs with more than two hidden layers, which has been confirmed by many theoretical results and a number of simulations in various engineering fields. Moreover, according to Kecman [63] it is recommendable to start the solving of a problem by using a model with one hidden layer.

By choosing the optimal number of neurons, it is necessary to avoid two extreme cases: omission of basic functions (insufficient number of hidden neurons) and overfitting (too many hidden neurons). In order to achieve proper generalisation "power" of an ANN model, it is necessary to apply the cross-validation procedure, owing it to the fact that good results during the training process do not guarantee proper generalisation "power." What is meant by generalisation is the "ability" of an ANN model to provide satisfactory results by using data which were not known to the model during the training (validation subset).

For the purpose of the cross-validation procedure within the training subset, 17 pseudorandomly chosen projects were taken, based on the same principle as within the testing subset, that is, the equal percentage share of projects in terms of value. If there is not too much difference, that is, deviation between estimated and expected values, percentage error (PE) or absolute percentage error (APE), or mean absolute percentage error (MAPE), in all three subsets (training, validation, and testing), it can be considered that this is the actual generalisation power of the formed ANN model, that is, that there is no "overfitting."

All the models for estimation of costs and duration were formed in the Statistica 12 software package, in which it is possible to define two types of ANN models, MLP (Multilayer Perceptron) and RBF (Radial Basis Function) models. According to Matignon [64], both models are used to deal with classification problems, while the MLP models are used to deal with regression problems and RBF models with clustering problems. Since the subject of the research involves the estimation of costs and duration, that is, belonging to regression problems, only the MLP ANN models were formed.

Activation function of output neurons is mainly linear when it comes to regression problems. When the activation functions of hidden neurons are concerned, the most commonly used functions are logistic unipolar and sigmoidal bipolar (hyperbolic tangent being the most commonly used one) [63]. In accordance with this recommendation for all the models, activation functions for hidden neurons logistic sigmoid and hyperbolic tangent were used, while the activation function identity was used for output neurons (Table 6).

\section{Results and Discussion}

Based on previously defined inputs, outputs, and defined parameters in each iteration, 10.000 ANN MLP models were formed, and one model with the smallest estimation error was chosen. The number of input and output neurons was defined by the number of inputs and outputs, whereas the number of 
TABLE 6: Activation functions of MLP ANN models.

\begin{tabular}{|c|c|c|c|}
\hline Function & Expression & Explanation & Range \\
\hline Identity & a & Activation of neurons is directly forwarded as output & $(-\infty,+\infty)$ \\
\hline Logistic sigmoid & $\frac{1}{1+\mathrm{e}^{-\mathrm{a}}}$ & "S" curve & $(0,1)$ \\
\hline Hyperbolic tangent & $\frac{\mathrm{e}^{\mathrm{a}}-\mathrm{e}^{-\mathbf{a}}}{\mathrm{e}^{\mathrm{a}}+\mathrm{e}^{-\mathbf{a}}}$ & $\begin{array}{c}\text { Sigmoid curve similar to logistic function, but featuring better } \\
\text { performances because of the symmetry it has. Ideal for MLP ANN } \\
\text { models, especially for hidden neurons }\end{array}$ & $(-1,+1)$ \\
\hline
\end{tabular}

TABLE 7: ANN models (min-max).

\begin{tabular}{lccccccc}
\hline Model & Network & $\begin{array}{c}\text { Activation } \\
\text { function hidden } \\
\text { neurons }\end{array}$ & $\begin{array}{c}\text { Activation } \\
\text { function output } \\
\text { neurons }\end{array}$ & $\begin{array}{c}\text { MAPE training } \\
\text { (cost) [\%] }\end{array}$ & $\begin{array}{c}\text { MAPE training } \\
\text { (duration) [\%] }\end{array}$ & $\begin{array}{c}\text { MAPE testing } \\
\text { (cost) [\%] }\end{array}$ & $\begin{array}{c}\text { MAPE testing } \\
\text { (duration) [\%] }\end{array}$ \\
\hline ANN 1 & MLP 12-4-2 & Tanh & Identity & 42.79 & 31.85 & 40.54 & 35.48 \\
ANN 2 & MLP 11-6-2 & Logistic & Identity & 41.88 & 31.82 & 26.97 & 30.22 \\
ANN 3 & MLP 12-6-1 & Tanh & Identity & 33.02 & $/$ & 25.38 & 26.88 \\
ANN 4 & MLP 11-7-1 & Tanh & Identity & 39.16 & $/$ & $/$ \\
ANN 5 & MLP 12-8-1 & Tanh & Identity & $/$ & 34.16 & 26.26 \\
ANN 6 & MLP 11-10-1 & Logistic & Identity & $/$ & 33.29 & $/$ & 35.16 \\
\hline
\end{tabular}

TABLE 8: ANN models (Zero-Mean).

\begin{tabular}{lccccccc}
\hline Model & Network & $\begin{array}{c}\text { Activation } \\
\text { function hidden } \\
\text { neurons }\end{array}$ & $\begin{array}{c}\text { Activation } \\
\text { function output } \\
\text { neurons }\end{array}$ & $\begin{array}{c}\text { MAPE training } \\
\text { (cost) [\%] }\end{array}$ & $\begin{array}{c}\text { MAPE training } \\
\text { (duration) [\%] }\end{array}$ & $\begin{array}{c}\text { MAPE testing } \\
\text { (cost) [\%] }\end{array}$ & $\begin{array}{c}\text { MAPE testing } \\
\text { (duration) [\%] }\end{array}$ \\
\hline ANN 7 & MLP 12-7-2 & Logistic & Identity & 52.16 & 30.89 & 37.96 & 34.23 \\
ANN 8 & MLP 11-8-2 & Logistic & Identity & 48.04 & 32.06 & 42.54 & 34.20 \\
ANN 9 & MLP 12-4-1 & Tanh & Identity & 37.49 & $/$ & $/$ & 20.22 \\
ANN 10 & MLP 11-8-1 & Tanh & Identity & 40.99 & $/$ & 32.32 & $/$ \\
ANN 11 & MLP 12-8-1 & Tanh & Identity & $/$ & 33.13 & $/$ & 37.20 \\
ANN 12 & MLP 11-5-1 & Tanh & Identity & $/$ & 35.59 \\
\hline
\end{tabular}

hidden neurons was limited to maximum of 10 . A total of 12 ANN models were chosen, 6 of them being normalised by the min-max procedure and the remaining 6 by the $Z$ Score procedure.

By using the ANN 1 and ANN 2 models, simultaneous estimation of costs and duration was carried out. The ANN 1 model had 12 inputs and 2 outputs, whereas the ANN 2 model was formed by using 11 inputs. Elimination of one input parameter followed the analysis of the influence of input parameters, which showed that the realisation zone (11i) has the smallest influence on the values of the output data. The same principle was applied in forming of ANN 3 and ANN 4 models for the estimation of costs only, as well as the ANN 5 and ANN 6 models for the estimation of time needed for the realisation of works.

Table 7 shows the chosen models (min-max normalisation) with defined characteristics of models and defined accuracy of estimation expressed through the MAPE.

Forming of the remaining 6 ANN models with data whose normalisation was performed by using the Zero-Mean normalisation was carried out in the same way. In this case as well the realisation zone (11i) has the smallest impact on the output values. Table 8 provides an outline of chosen models with defined characteristics of models and defined accuracy of estimation expressed through the MAPE.

The comparative analysis of presented models clearly shows that the greater accuracy of estimation is achieved by models formed based on the data prepared by the minmax normalisation procedure. The accuracy of estimation of formed models is unsatisfactory, that is, being considerably larger than the desirable $\pm 15 \%$ for the costs of construction.

The first step in the forming of models for estimation by using the SVM as well as the ANN models relates to defining of input and output data. In the process of forming of SVM models, the used data had previously been prepared by applying the min-max normalisation, as it was proved that using it results in the greater accuracy in the case of ANN models. Moreover, only the models for separate estimation of costs and duration of construction were formed. The main reason for this lies in the fact that the greater accuracy is achieved by separate estimation, that is, by forming of separate models, which was proved on the ANN models. However, the software package Statistica 12 itself does not provide the option of simultaneous estimation of several parameters by using the 
TABLE 9: Functions of error of SVM models.

\begin{tabular}{lrr}
\hline SVM type & Error function & Minimize subject to \\
\hline Type 1 & $\frac{1}{2} w^{T} w+C \sum_{i=1}^{N} \xi_{i}+C \sum_{i=1}^{N} \xi_{i}{ }_{i}$ & $\begin{array}{c}w^{T} \phi\left(x_{i}\right)+b-y_{i} \leq \varepsilon+\xi^{*}{ }_{i} \\
y_{i}-w^{T} \phi\left(x_{i}\right)-b_{i} \leq \varepsilon+\xi_{i} \\
\xi_{i}, \xi^{*}{ }_{i} \geq 0, i=1, N\end{array}$ \\
\hline Type 2 & $\frac{1}{2} w^{T} w-C\left(v \varepsilon+\frac{1}{N} \sum_{i=1}^{N}\left(\xi_{i}+\xi^{*}{ }_{i}\right)\right)$ & $\left(w^{T} \phi\left(x_{i}\right)+b\right)-y_{i} \leq \varepsilon+\xi^{*}{ }_{i}$ \\
& & $y_{i}-\left(w^{T} \phi\left(x_{i}\right)+b_{i}\right) \leq \varepsilon+\xi_{i}$ \\
$\xi_{i}, \xi^{*}{ }_{i} \geq 0, i=1, N, \varepsilon \geq 0$
\end{tabular}

TABLE 10: SVM models (min-max).

\begin{tabular}{lccccccc}
\hline Model & $C$ & $\varepsilon$ & $\frac{1}{2 \sigma^{2}}$ & $\begin{array}{c}\text { MAPE training } \\
\text { (cost) [\%] }\end{array}$ & $\begin{array}{c}\text { MAPE training } \\
\text { (duration) [\%] }\end{array}$ & $\begin{array}{c}\text { MAPE testing } \\
\text { (cost) [\%] }\end{array}$ & $\begin{array}{c}\text { MAPE testing } \\
(\text { duration) [\%] }\end{array}$ \\
\hline SVM 1 & 20 & 0.001 & 0.083 & 25.28 & $/$ & 15.47 & $/$ \\
SVM 2 & 20 & 0.001 & 0.091 & 23.96 & $/$ & 7.06 & $/$ \\
SVM 3 & 20 & 0.001 & 0.083 & $/$ & 29.21 & 3 \\
SVM 4 & 20 & 0.001 & 0.091 & $/$ & 30.75 & $/$ \\
\hline
\end{tabular}

SVM. Within the mentioned software package, two functions of error in the forming of SVM models are offered (Table 9).

For Type 1 (epsilon-SVM regression) it is necessary to define parameter capacity $(C)$ and epsilon $(\varepsilon)$, insensitivity zone. At the same time, for Type 2 (nu-SVM regression) it is necessary to define parameter capacity $(C)$ and $\mathrm{Nu}(\gamma)$. The value of parameters $\mathbf{C}$ and $\boldsymbol{\varepsilon}$ ranges between 0 and $\infty$, whereas the value of parameter $\gamma$ ranges between 0 and 1 . It is also necessary to choose one of the offered Kernel functions: linear, polynomial, RBF, or sigmoid. RBF kernel function presents the most frequently used kernel function for forming of SVM models:

$$
\mathbf{K}\left(\mathbf{x}_{\mathbf{i}}, \mathbf{x}_{\mathbf{j}}\right)=\exp \left(-\frac{1}{2 \sigma^{2}}\left\|\mathbf{x}-\mathbf{x}_{\mathbf{i}}\right\|^{2}\right) \quad \boldsymbol{\sigma} \text { - width of RBF function. }
$$

When using the RBF kernel function it is necessary to define the parameter $\gamma=\mathbf{1} / \mathbf{2} \sigma^{2}$. For the purpose of forming of the model, the function of error Type 1 was used.

A total of four SVM models were formed, with the same number of input parameters as in the case of ANN models, from the perspective of input parameters SVM $1=\mathrm{ANN}$ 3 and ANN 9, SVM $2=$ ANN 4 and ANN 10, SVM $3=$ ANN 5 and ANN 11, and SVM $4=$ ANN 6 and ANN 12. The reason for this is the easier comparative analysis of results obtained by using the listed models. Table 10 shows characteristics of formed models with defined accuracy of estimation expressed through the MAPE.

After forming the SVM models, it is evident that they provide greater accuracy of estimation of both costs and duration of projects as well. The shown accuracy of estimation made through the MAPE is not sufficient for the choice of a model, but it is necessary to carry out the analysis of accuracy of estimation for each of the projects separately, especially those from the testing subset. The estimation error is expressed through the $\mathrm{PE}$ (percentage error), which is shown in Table 11 for the estimation of costs and in Table 12 for the estimation of duration of projects. Defining of the PE is of particular importance for the estimation of costs, in order to carry out the comparative analysis with the desired accuracy of $\pm 15 \%$ for each of the projects from the testing set separately.

Errors in the estimation of duration are higher when compared to estimation of offered prices for the realisation of works, since the investor defined in the tender documentation the maximum possible duration of works, which is more than an optimistic prediction. In other words, the offered time is not the result of the estimation by the contractor, but the limitation set by the investor. For this reason, contractors adopted automatically the maximum offered duration of works.

Additionally, it can be stated that models for separate estimation of costs and duration provide a higher level of accuracy than those which carry the estimation out simultaneously, which is specifically the case with ANN models. The reason for this lies in the fact that the impact of input parameters on the output ones is not the same for the estimation of costs and duration of works.

Figure 1 shows the influence of input parameters on the output ones in the case of estimation of costs, for the ANN 3 and ANN 4 models. The input data are divided into four categories, that is, two groups and two independent pieces of input data. The first group presents inputs which relate to amounts of materials needed for the realisation of works on the roadway construction and landscaping; the second one relates to the share of works by the remaining groups of works from the bill of works, whereas the independent input data relates to the realisation zone and the category of the project.

Figure 2 Illustrates the influence of input parameters for the ANN 5 and ANN 6 models, that is, models for the estimation of duration of projects.

Based on the graphs given above, it can clearly be noticed that the second group of input data has a considerably greater influence on the estimation of project duration, diminishing the influence of the first group. Moreover, the category of the project is of approximately the same significance for the 
TABLE 11: PE for estimation of costs, testing set.

\begin{tabular}{|c|c|c|c|c|c|c|c|}
\hline & \multirow{2}{*}{ Expected cost [RSD] } & \multicolumn{6}{|c|}{ PE for the cost for the model testing [\%] } \\
\hline & & ANN 1 & ANN 2 & ANN 3 & ANN 4 & SVM 1 & SVM 2 \\
\hline$(1)$ & $2.648 .222,52$ & -102.64 & 50.14 & 7.02 & -22.16 & 35.13 & 29.26 \\
\hline$(2)$ & $3.745 .996,06$ & -135.49 & 24.81 & -64.12 & -6.85 & 10.90 & 2.95 \\
\hline$(3)$ & $4.316 .450,20$ & -71.75 & -3.35 & -58.63 & -4.19 & 3.30 & -3.69 \\
\hline$(4)$ & $4.406 .745,87$ & -8.84 & -28.48 & -26.43 & 43.85 & -101.06 & -17.16 \\
\hline$(5)$ & $5.894 .577,64$ & -61.60 & -56.76 & -30.47 & -71.95 & 6.58 & -6.68 \\
\hline (6) & $6.228 .262,97$ & 108.17 & 61.10 & 58.49 & 70.07 & -0.36 & 11.47 \\
\hline (7) & 7.959.531,14 & -8.24 & -22.17 & -26.71 & -45.93 & -21.82 & -14.67 \\
\hline$(8)$ & $14.402 .129,26$ & -25.13 & -10.58 & 12.93 & 27.89 & -31.66 & 3.81 \\
\hline (9) & $15.499 .081,98$ & -33.01 & -15.10 & -25.31 & -23.05 & 6.85 & 6.93 \\
\hline (10) & $24.298 .158,68$ & -11.78 & 55.89 & -11.72 & -5.09 & -6.95 & 2.46 \\
\hline (11) & $29.293 .376,43$ & -6.23 & -1.86 & -2.24 & -18.82 & 0.25 & 0.19 \\
\hline (12) & $31.331 .583,69$ & -22.66 & -17.92 & -9.52 & -23.11 & -6.58 & -3.87 \\
\hline (13) & $48.628 .946,36$ & -12.12 & -37.33 & 4.69 & 6.09 & -4.72 & 2.68 \\
\hline (14) & $68.428 .523,13$ & -61.68 & -25.73 & -58.10 & -51.68 & -13.91 & -6.86 \\
\hline (15) & $74.828 .211,00$ & 8.16 & 25.96 & 7.08 & 4.65 & 7.95 & 4.28 \\
\hline (16) & $121.971 .479,98$ & 6.97 & 11.85 & 26.16 & 30.90 & 2.68 & 1.90 \\
\hline \multirow[t]{2}{*}{ (17) } & 267.333.894,15 & -4.63 & -9.51 & -1.91 & -0.62 & -2.31 & -1.21 \\
\hline & MAPE & 40.54 & 26.97 & 25.38 & 26.88 & 15.47 & 7.06 \\
\hline
\end{tabular}

TABLE 12: PE for estimation of duration, testing set.

\begin{tabular}{|c|c|c|c|c|c|c|c|}
\hline & \multirow{2}{*}{ Expected duration [day] } & \multicolumn{6}{|c|}{ PE for the duration of the model testing subset [\%] } \\
\hline & & ANN 1 & ANN 2 & ANN 5 & ANN 6 & SVM 3 & SVM 4 \\
\hline (1) & 12 & -26.88 & -27.47 & -20.84 & -17.89 & -29.45 & -69.18 \\
\hline (2) & 26 & 49.00 & 14.41 & 14.84 & 37.66 & 6.31 & -2.46 \\
\hline (3) & 20 & 11.24 & -4.21 & 7.70 & 24.81 & -4.03 & -7.53 \\
\hline (4) & 35 & -0.63 & 1.07 & 9.13 & -45.02 & 11.06 & 28.42 \\
\hline (5) & 34 & 19.86 & 22.68 & 13.73 & 29.95 & 35.81 & 36.24 \\
\hline (6) & 17 & 34.71 & 26.11 & -13.14 & -12.66 & -5.80 & 0.01 \\
\hline (7) & 17 & -39.19 & -27.34 & -21.32 & 35.01 & 31.42 & 27.06 \\
\hline (8) & 20 & -86.38 & -38.59 & -57.30 & -93.00 & -83.95 & -41.62 \\
\hline (9) & 25 & 3.90 & -14.67 & -3.53 & -2.19 & 5.42 & -0.93 \\
\hline (10) & 35 & -16.14 & 13.57 & -0.55 & 6.17 & -28.22 & -1.72 \\
\hline (11) & 25 & -61.40 & -62.19 & -55.17 & -54.97 & -17.28 & -23.71 \\
\hline (12) & 38 & 0.66 & -14.99 & 0.85 & -1.74 & 21.63 & 19.26 \\
\hline (13) & 41 & -124.67 & -123.00 & -113.63 & -103.76 & -66.12 & -63.11 \\
\hline (14) & 60 & -51.47 & -53.54 & -47.83 & -56.72 & -23.93 & -24.82 \\
\hline (15) & 60 & 42.08 & 43.97 & 37.67 & 44.03 & 17.42 & 13.95 \\
\hline (16) & 60 & -29.36 & -24.88 & -17.08 & -30.75 & -22.26 & -19.72 \\
\hline (17) & 75 & 5.61 & 1.09 & 12.14 & 1.29 & 7.95 & 7.29 \\
\hline & MAPE & 35.48 & 30.22 & 26.26 & 35.16 & 24.59 & 22.77 \\
\hline
\end{tabular}

estimation of both costs and duration as well, whereas the realisation zone has a considerably greater impact on the estimation of duration of the project.

\section{Conclusions}

Based on the results presented above, a conclusion was drawn that a greater accuracy level in estimating of costs and duration of construction is achieved by using of models for separate estimation of costs and duration. The reason for this lies primarily in the different influence of input parameters on the estimation of costs in comparison with the estimation of duration of the project. By integrating them into a single model a compromise in terms of the significance of input data is made, resulting in the lower precision of estimation when it comes to ANN models. 


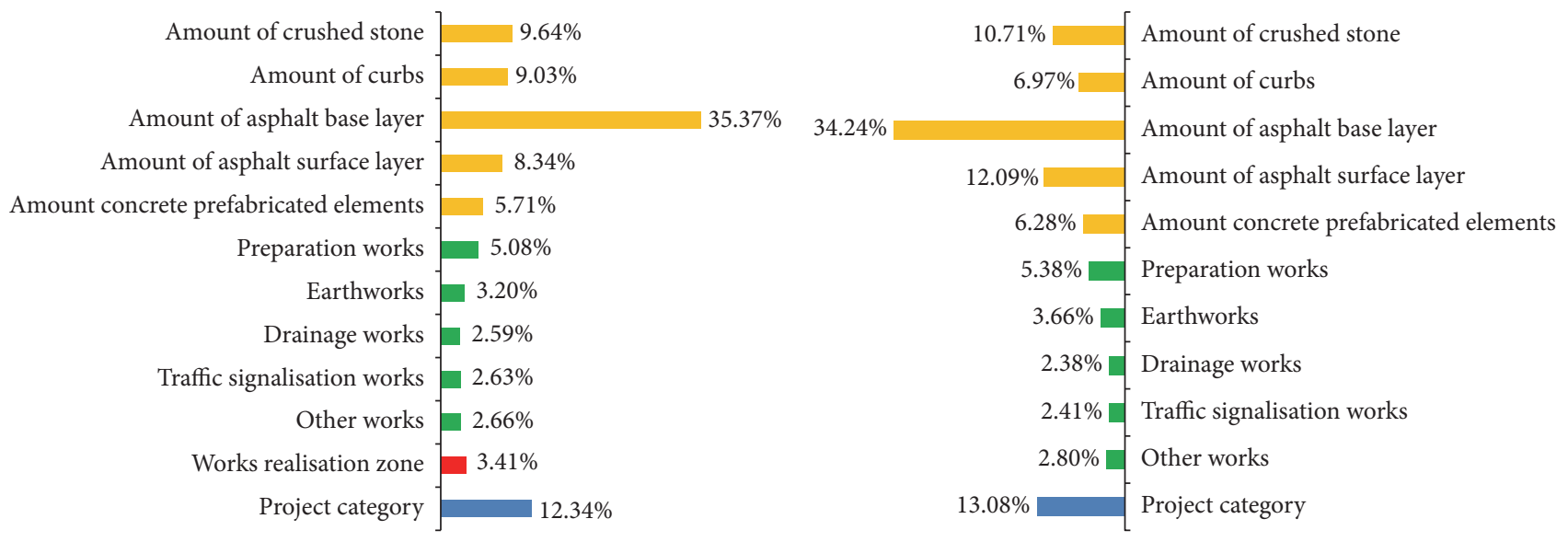

FIGURE 1: Analysis of sensitivity (ANN 3 and ANN 4); estimation of construction costs.

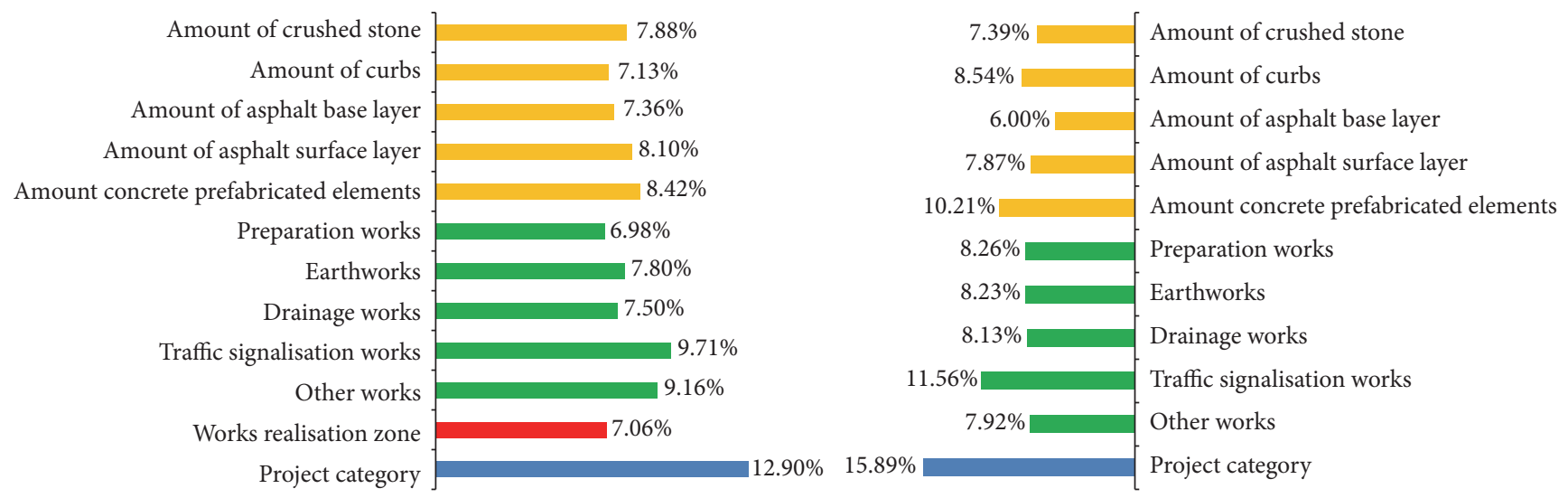

FIGURE 2: Analysis of sensitivity (ANN 5 and ANN 6); estimation of duration of construction.

SVM models feature a greater capacity of generalisation, providing at the same time greater accuracy of estimation, for the estimation of both costs and duration of projects as well. In both cases, the greatest accuracy of estimation is achieved by the SVM model with 11 input parameters, that is, without a more considerable influence of the project realisation zone, which implies that the investors did not pay particular attention when defining the offered price and time to whether the works will be realised within the city zone or the suburbs.

Extending of the data base in terms of the very subject of a contract, that is, the future construction object, and the introduction of parameters, such as the length of the section, the roadway width, the urban road category (boulevard, side alley, etc.), the length of cycling lanes, areas intended for parking, pedestrian lanes, and plateaus, would widely extend the possibility of application of estimation models. There is a wide range of potential parameters which can be introduced as the feature of the construction object, presenting at the same time the input data for the estimation model. In this way, the possibility of estimating the costs and duration of construction in the contracting phase not only when the bill of works is defined (query by tender), but also when the investor defines only the guidelines, that is, the conditions that the future construction object has to meet (query by functional parameters of a future object), is created. Forming of a model with functional features of a future construction object as input parameters could have a double application from both perspectives, of the investor and the contractor. From the perspective of the investor, if the accuracy of estimation similar to that of already formed models was achieved, the precision in estimation in the initial phase and defining of criteria, which the future object is to meet, would be considerably above the one required by the literature $( \pm 50 \%)[10]$.

The research was conducted for the estimation of costs and duration of realisation for "build" contracts. This approach provides an option to estimate "design-build" contracts as well; that is, the experience gained through "build" contracts can be used in future estimations of "design-build" contacts, for both the needs of the investor and the contractor as well. Application of future models largely depends on the available information at the time of estimation. For this reason, the input data should be adjusted to the available information at the given moment, for both the investor and the contractor as well. 


\section{Conflicts of Interest}

The authors declare that there are no conflicts of interest regarding the publication of this paper.

\section{Acknowledgments}

The work reported in this paper is a part of the investigation within the research project "Utilization of By-Products and Recycled Waste Materials in Concrete Composites in The Scope of Sustainable Construction Development in Serbia: Investigation and Environmental Assessment of Possible Applications," supported by the Ministry of Education, Science and Technological Development, Republic of Serbia (TR 36017). This support is gratefully acknowledged. The work reported in this paper is also a part of the investigation within the research project "Optimization of Architectural and Urban Planning and Design in Function of Sustainable Development in Serbia," supported by the Ministry of Education, Science and Technological Development, Republic of Serbia (TR 36042). This support is gratefully acknowledged.

\section{References}

[1] J. Gunner and M. Skitmore, "Comparative analysis of pre-bid forecasting of building prices based on Singapore data," Construction Management and Economics, vol. 17, no. 5, pp. 635646, 1999.

[2] N. Morrison, “The accuracy of quantity surveyors' cost estimating," Construction Management and Economics, vol. 2, no. 1, pp. 57-75, 1984.

[3] M. Skitmore and H. P. Lo, "A method for identifying high outliers in construction contract auctions," Engineering, Construction and Architectural Management, vol. 9, no. 2, pp. 90-130, 2002.

[4] M. A. Azman, Z. Abdul-Samad, and S. Ismail, "The accuracy of preliminary cost estimates in Public Works Department (PWD) of Peninsular Malaysia," International Journal of Project Management, vol. 31, no. 7, pp. 994-1005, 2013.

[5] A. A. Aibinu and T. Pasco, "The accuracy of pre-tender building cost estimates in Australia," Construction Management and Economics, vol. 26, no. 12, pp. 1257-1269, 2008.

[6] S. M. Abou Rizk, G. M. Babey, and G. Karumanasseri, "Estimating the cost of capital projects: An empirical study of accuracy levels for municipal government projects," Canadian Journal of Civil Engineering, vol. 29, no. 5, pp. 653-661, 2002.

[7] J. S. Shane, K. R. Molenaar, S. Anderson, and C. Schexnayder, "Construction project cost escalation factors," Journal of Management in Engineering, vol. 25, no. 4, pp. 221-229, 2009.

[8] M. Skitmore, "Raftery curve construction for tender price forecasts," Construction Management and Economics, vol. 20, no. 1, pp. 83-89, 2002.

[9] B. Ivković and Ž. Popović, Upravljanje projektima u građevinarstvu. Građevinska knjiga, Beograd, 2005.

[10] A. Ashworth, Cost Studies of Buildings, Pearson Education Limited, England, UK, 5th edition, 2010.

[11] M. Asif and R. M. W. Horner, Economical Construction Design Using Simple Cost Models, University of Dundee, 1989.

[12] R. M. Horner, K. J. McKay, and M. M. Saket, "Cost-significance in Estimating and Control, Symposium Organization in Construction," in Proceedings of the Cost-significance in Estimating and Control, Symposium Organization in Construction, pp. 571585, Opatija, Croatia, 1986.

[13] H. Adeli, "Neural networks in civil engineering: 1989-2000," Computer-Aided Civil and Infrastructure Engineering, vol. 16, no. 2, pp. 126-142, 2001.

[14] A. M. Elazouni, I. A. Nosair, Y. A. Mohieldin, and A. G. Mohamed, "Estimating resource requirements at conceptual design stage using neural networks," Journal of Computing in Civil Engineering, vol. 11, no. 4, pp. 217-223, 1997.

[15] V. Albino and A. C. Garavelli, "A neural network application to subcontractor rating in construction firms," International Journal of Project Management, vol. 16, no. 1, pp. 9-14, 1998.

[16] A. W. T. Leung, C. M. Tam, and D. K. Liu, "Comparative study of artificial neural networks and multiple regression analysis for predicting hoisting times of tower cranes," Building and Environment, vol. 36, no. 4, pp. 457-467, 2001.

[17] S. Rebaño-Edwards, "Modelling perceptions of building quality-A neural network approach," Building and Environment, vol. 42, no. 7, pp. 2762-2777, 2007.

[18] D. Vouk, D. Malus, and I. Halkijevic, "Neural networks in economic analyses of wastewater systems," Expert Systems with Applications, vol. 38, no. 8, pp. 10031-10035, 2011.

[19] J.-H. Chen and S. C. Hsu, "Hybrid ANN-CBR model for disputed change orders in construction projects," Automation in Construction, vol. 17, no. 1, pp. 56-64, 2007.

[20] N. B. Chaphalkar, K. C. Iyer, and S. K. Patil, "Prediction of outcome of construction dispute claims using multilayer perceptron neural network model," International Journal of Project Management, vol. 33, no. 8, article no. 1808, pp. 1827-1835, 2015.

[21] H. P. Tserng, G.-F. Lin, L. K. Tsai, and P.-C. Chen, "An enforced support vector machine model for construction contractor default prediction," Automation in Construction, vol. 20, no. 8, pp. 1242-1249, 2011.

[22] K. C. Lam, E. Palaneeswaran, and C.-Y. Yu, "A support vector machine model for contractor prequalification," Automation in Construction, vol. 18, no. 3, pp. 321-329, 2009.

[23] M. Y. Cheng and A. F. V. Roy, "Evolutionary fuzzy decision model for cash flow prediction using time-dependent support vector machines," International Journal of Project Management, vol. 29, no. 1, pp. 56-65, 2011.

[24] M. Wauters and M. Vanhoucke, "Support Vector Machine Regression for project control forecasting," Automation in Construction, vol. 47, pp. 92-106, 2014.

[25] V. Mučenski, M. Trivunić, G. Ćirović, I. Peško, and J. Dražić, "Estimation of recycling capacity of multistorey building structures using artificial neural networks," in Acta Polytechnica Hungarica, vol. 10, pp. 175-192, 4 edition, 2013.

[26] S. O. Cheung, P. S. P. Wong, A. S. Y. Fung, and W. V. Coffey, "Predicting project performance through neural networks," International Journal of Project Management, vol. 24, no. 3, pp. 207-215, 2006.

[27] H. M. Günaydin and S. Z. Doğan, "A neural network approach for early cost estimation of structural systems of buildings," International Journal of Project Management, vol. 22, no. 7, pp. 595-602, 2004.

[28] M. Arafa and M. Alqedra, "Early stage cost estimation of buildings construction projects using artificial neural networks," Journal of Artificial Intelligence Research, vol. 4, no. 1, pp. 63-75, 2011.

[29] M. Bouabaz and M. Hamami, "A cost estimation model for repair bridges based on artificial neural network," American Journal of Applied Sciences, vol. 5, no. 4, pp. 334-339, 2008. 
[30] D. P. Alex, M. Al Hussein, A. Bouferguene, and S. Fernando, "Artificial neural network model for cost estimation: City of edmonton's water and sewer installation services," Journal of Construction Engineering and Management, vol. 136, no. 7, pp. 745-756, 2010.

[31] I. Siqueira, Neural Network-Based Cost Estimating, [Master, thesis], University of Montreal, Quebec, Department of Building, Civil and Environmental Engineering, Canada, 1999.

[32] S.-H. An, U.-Y. Park, K.-I. Kang, M.-Y. Cho, and H.-H. Cho, "Application of support vector machines in assessing conceptual cost estimates," Journal of Computing in Civil Engineering, vol. 21, no. 4, pp. 259-264, 2007.

[33] H. Adeli and M. Wu, "Regularization neural network for construction cost estimation," Journal of Construction Engineering and Management, vol. 124, no. 1, pp. 18-24, 1998.

[34] C. G. Wilmot and B. Mei, "Neural network modeling of highway construction costs," Journal of Construction Engineering and Management, vol. 131, no. 7, pp. 765-771, 2005.

[35] B. Vahdani, S. M. Mousavi, M. Mousakhani, M. Sharifi, and H. Hashemi, "A neural network modela based on support Vector machine for conceptual cost estimation in construction projects," Journal of Optimization in Industrial Engineering, vol. 10, p. 11, 2012.

[36] F. Kong, X.-J. Wu, and L.-Y. Cai, "A novel approach based on support vector machine to forecasting the construction project cost," in Proceedings of the 2008 International Symposium on Computational Intelligence and Design (ISCID '08), pp. 21-24, China, October 2008.

[37] F. Kong, X. Wu, and L. Cai, "Application of RS-SVM in construction project cost forecasting," in Proceedings of the 4th International Conference on Wireless Communications, Networking and Mobile Computing (WiCOM '08), Dalian, China, October 2008.

[38] G. Kim, J. Shin, S. Kim, and Y. Shin, "Comparison of School Building Construction Costs Estimation Methods Using Regression Analysis, Neural Network, and Support Vector Machine," Journal of Building Construction and Planning Research, vol. 01, no. 01, pp. 1-7, 2013.

[39] G. H. Kim, S. H. An, and K. I. Kang, "Comparison of construction cost estimating models based on regression analysis, neural networks, and case-based reasoning," Building and Environment, vol. 39, no. 10, pp. 1235-1242, 2004.

[40] R. Sonmez, "Conceptual cost estimation of building projects with regression analysis and neural networks," Canadian Journal of Civil Engineering, vol. 31, no. 4, pp. 677-683, 2004.

[41] G. H. Kim, D. S. Seo, and K. I. Kang, "Hybrid models of neural networks and genetic algorithms for predicting preliminary cost estimates," Journal of Computing in Civil Engineering, vol. 19, no. 2, pp. 208-211, 2005.

[42] W. F. Feng, W. J. Zhu, and Y. G. Zhou, “The application of genetic algorithm and neural network in construction cost estimate," in Proceedings of the Third International Symposium on Eletronic Commerce and Security Workshop (ISECS '10), pp. 151155, Guangzhou, China, 2010.

[43] M. Y. Cheng and C. J. Huang, "Construction Conceptual Cost Estimates Using Evolutionary Fuzzy Neural Inference Model," in Proceedings of the 20th International Symposium on Automation and Robotics in Construction, pp. 595-600, Eindhoven, The Netherlands, September 2003.

[44] M.-Y. Cheng, H.-C. Tsai, and E. Sudjono, "Conceptual cost estimates using evolutionary fuzzy hybrid neural network for projects in construction industry," Expert Systems with Applications, vol. 37, no. 6, pp. 4224-4231, 2010.
[45] M. Cheng and Y. Wu, "Construction Conceptual Cost Estimates Using Support Vector Machine," in Proceedings of the 22nd International Symposium on Automation and Robotics in Construction, pp. 1-5, Ferrara, Italy, September 2005.

[46] S. G. Deng and T. H. Yeh, "Using least squares support vector machine to the product cost estimation," vol. 25, no. 1, pp. 1-16, 2011.

[47] M. Y. Cheng, H. S. Peng, Y. W. Wu, and T. L. Chen, "Estimate at completion for construction projects using evolutionary support vector machine inference model," Automation in Construction, vol. 19, no. 5, pp. 619-629, 2010.

[48] X.-Z. Wang, X.-C. Duan, and J.-Y. Liu, "Application of neural network in the cost estimation of highway engineering," Journal of Computers, vol. 5, no. 11, pp. 1762-1766, 2010.

[49] H. Al-Tabtabai, A. P. Alex, and M. Tantash, "Preliminary cost estimation of highway construction using neural networks," Cost Engineering, vol. 41, no. 3, pp. 19-24, 1999.

[50] T. Hegazy and A. Ayed, "Neural network model for parametric cost estimation of highway projects," Journal of Construction Engineering and Management, vol. 124, no. 3, pp. 210-218, 1998.

[51] J. Sodikov, "Cost estimation of highway projects in developing countries: artificial neural network approach," Journal of the Eastern Asia Society for Transportation Studies, vol. 6, pp. 10361047, 2005.

[52] N. I. El-Sawahli, "Support vector machine cost estimation model for road projects," Journal of Civil Engineering and Architecture, vol. 9, pp. 1115-1125, 2015.

[53] A. Attal, Development of neural network models for prediction of highway construction cost and project duration [Master, thesis], Department of Civil Engineering and the Russ College of Engineering and Technology, Ohio University, Ohio, Ohio, USA, 2010.

[54] S. Bhokha and S. O. Ogunlana, "Application of artificial neural network to forecast construction duration of buildings at the predesign stage," Engineering, Construction and Architectural Management, vol. 6, no. 2, pp. 133-144, 1999.

[55] B. Hola and K. Schabowicz, "Estimation of earthworks execution time cost by means of artificial neural networks," Automation in Construction, vol. 19, no. 5, pp. 570-579, 2010.

[56] Y.-R. Wang, C.-Y. Yu, and H.-H. Chan, "Predicting construction cost and schedule success using artificial neural networks ensemble and support vector machines classification models," International Journal of Project Management, vol. 30, no. 4, pp. 470-478, 2012.

[57] I. Peško, G. Ćirović, V. Mučenski, and Ž. Tepić, "Analysis and preparation of date in neural networks calculation stage for the purpose of creating business proposals," in Proceedings of the 10th International Conference Organization, Technology and Management in Construction, Book of Abstracts, p. 57, Šibenik, Croatia, September 2011.

[58] I. Peško, M. Trivunić, G. Ćirović, and V. Mučenski, "A preliminary estimate of time and cost in urban road construction using neural networks," Tehnički vjesnik, vol. 3, no. 20, pp. 563-570, 2013.

[59] R. D. Stewart, R. M. Wyskida, and J. D. Johannes, Cost Estimator's Reference Manual, John Wiley \& Sons, USA, 1995.

[60] D. S. Remer and H. R. Buchanan, "Estimating the cost for doing a cost estimate," International Journal of Production Economics, vol. 66, no. 2, pp. 101-104, 2000.

[61] F. J. M. Lopez, S. M. Puertas, and J. A. T. Arriaza, "Training of support vector machine with the use of multivariate normalization," Applied Soft Computing, vol. 24, pp. 1105-1111, 2014. 
[62] W. Y. Huang and R. P. Lipmann, Neural Net and Traditional Classifiers u Neural Information Processing Systems, D. Z. Anderson, Ed., American Institute of Physics, New York, NY, USA, 1988.

[63] V. Kecman, Learning and Soft Computing, Support Vector Machines, Neural Networks and Fuzzy Logic Models, Massachusetts Institute of Technology (MIT), Massachusetts, Mass, USA, 2001.

[64] R. Matignon, Neural Networks Modeling using SAS Enterprise MIner, ISBN: 1-4184-2341-6, 2005. 


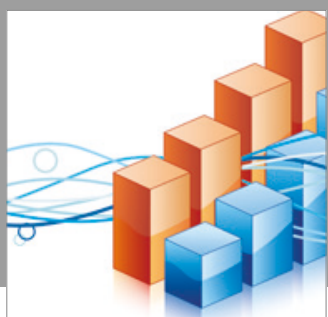

Advances in

Operations Research

vatersals

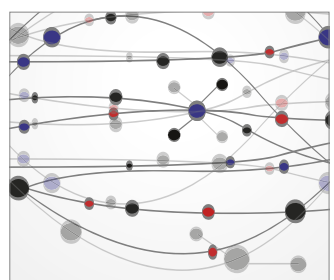

\section{The Scientific} World Journal
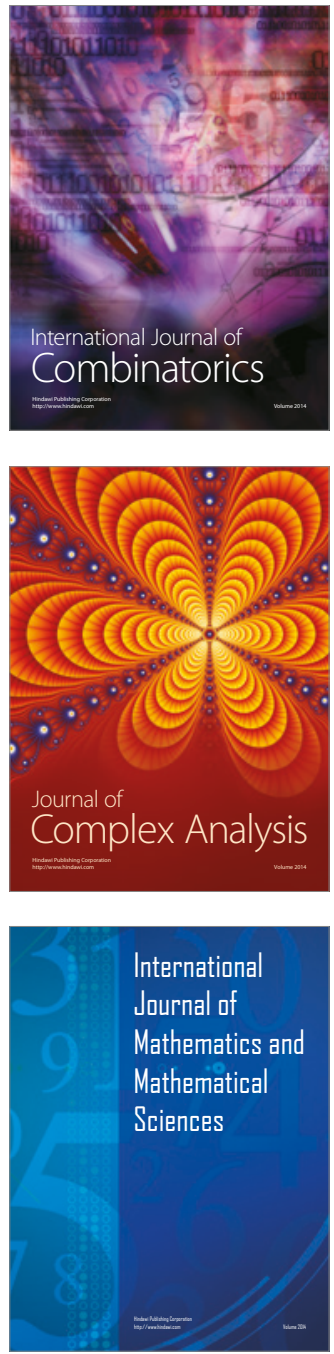
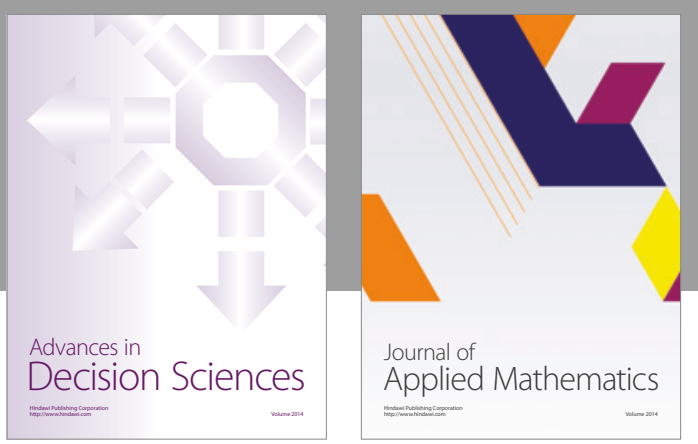

Algebra

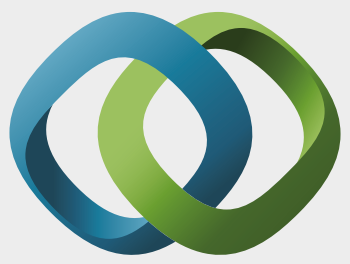

\section{Hindawi}

Submit your manuscripts at

https://www.hindawi.com
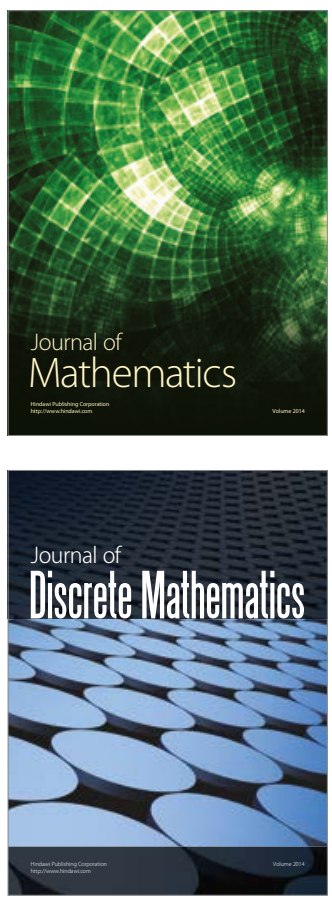

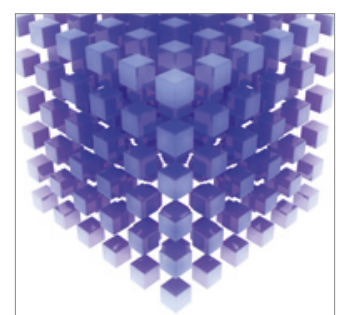

Mathematical Problems in Engineering
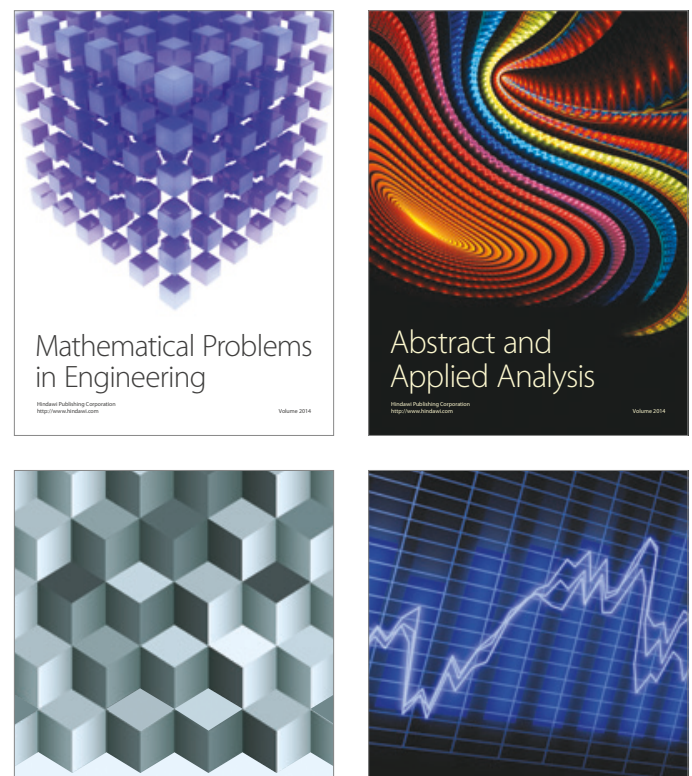

Journal of

Function Spaces

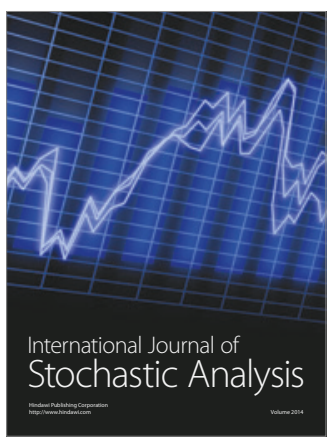

Probability and Statistics
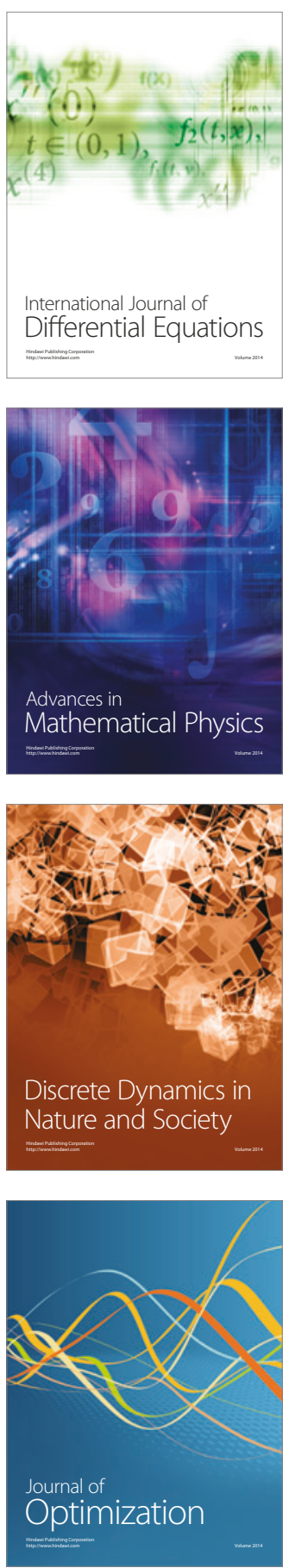